\title{
Estimation of Landslides and Road Capacity after August 8, 2017, MS7.0 Jiuzhaigou Earthquake Using High-Resolution Remote Sensing Images
}

\author{
Xiao Fu, ${ }^{1}$ Qing Zhu, ${ }^{1}$ Chao Liu, ${ }^{2,3}$ Naiwen Li, ${ }^{2,3}$ Wenhua Zhuang, ${ }^{3,4}$ Zhengli Yang, $^{2,3}$ \\ Heng Lu $\mathbb{B},{ }^{2,3}$ and Min Tang ${ }^{5}$ \\ ${ }^{1}$ Faculty of Geosciences and Environmental Engineering, Southwest Jiaotong University, Chengdu 611756, China \\ ${ }^{2}$ State Key Laboratory of Hydraulics and Mountain River Engineering, Sichuan University, Chengdu 610065, China \\ ${ }^{3}$ College of Hydraulic and Hydroelectric Engineering, Sichuan University, Chengdu 610065, China \\ ${ }^{4}$ Sichuan Academy of Forestry, Chengdu, Sichuan, 610081, China \\ ${ }^{5}$ China Railway Eryuan Engineering Group Co., Ltd., Chengdu 610031, China
}

Correspondence should be addressed to Heng Lu; luheng@scu.edu.cn

Received 16 June 2020; Revised 22 October 2020; Accepted 31 October 2020; Published 19 November 2020

Academic Editor: Chong Xu

Copyright ( $\odot 2020$ Xiao Fu et al. This is an open access article distributed under the Creative Commons Attribution License, which permits unrestricted use, distribution, and reproduction in any medium, provided the original work is properly cited.

\begin{abstract}
On 8 August 2017, Jiuzhaigou earthquake, magnitude 7.0, hit northern Sichuan, China. As the earthquake-stricken area is located in the mountainous region with forest and low residential density, the main damage is to vegetation and roads by earthquaketriggered landslides. In this study, the core area of Jiuzhaigou natural reserve, one of the highest seismic intensity zones, is selected. The landslides are extracted by examining vegetation changes from the preearthquake and postearthquake images using the Normalized Difference Vegetation Index (NDVI) and are verified by slope. As most road damage in the mountainous region could be attributed to the landslides nearby, the impacts of landslide on road are studied based on spatial analysis and are used to infer occluded road damage. Then, a knowledge-based method for postearthquake road detection and road capacity assessment from preearthquake road data and postearthquake high-resolution remote sensing imagery is proposed, as well as the quantitative road capacity assessment indicators to classify the road grades. This method is evaluated using the Beijing-2 (BJ-2) satellite images over the study area acquired on 28 April and 9 August. Compared with visual interpretation results, the extraction accuracy reached $90 \%$ for landslides and $85 \%$ for postearthquake roads, indicating that the approaches are effective and promising for quick response to devastating earthquake in similar circumstances.
\end{abstract}

\section{Introduction}

On 8 August 2017, an earthquake (magnitude 7.0) hit Jiuzhaigou County, Sichuan Province, China. The epicenter was located in Bimang village, $5 \mathrm{~km}$ west of the core area of Jiuzhaigou natural reserve. As the earthquake-stricken areas are mountainous and alpine with comparatively low population density, the number of casualties and collapsed buildings is not as huge as expected. However, the earthquake triggered numerous landslides, leading to great damage to roads, because of the geological structure as well as the impacts of the Wenchuan earthquake (MS 8.0, 2008) and Lushan earthquake (7.0 Ms 7.0, 2013) in Sichuan [1-12]. Quickly identifying the spatial distribution of landslides and estimating road capacity can be of great importance for the access of rescue teams and subsequent quake-relief efforts.

The assessment of postearthquake landslides and road capacity relies on field surveys and remote sensing. Field surveys can obtain the on-site detailed information of landslides and road damage, but they are limited when the sites are inaccessible because of geological hazards or transportation restrictions, regardless of the high cost and regional communication outage [13, 14]. With sensors mounted on satellites or planes, remote sensing can overcome 
these limitations. High-resolution imageries have been extensively used in postearthquake damage assessment $[15,16]$. In terms of earthquake-triggered landslides' detection, preand postevent remote sensing images covering the same area have been used to compare the land cover changes [17-19]. Integrated with a digital elevation model and GIS data, single postevent images can also capture the distribution of landslides by using density slicing or spectral enhancement techniques [20,21]. For road extraction, most of the methods comprise one or more algorithms. The backpropagation (BP) neural algorithm was proposed in the late 1980s [22] and has been improved by many researchers $[23,24]$. A multiclass SVM method including image segmentation and classification algorithms was proposed [25] which performs well for multispectral data. These are supervised classification methods demanding better and more training samples for higher accuracy. Unsupervised classification methods do not need training samples. For example, mean-shift algorithm can use kernel density to estimate roads' factors without parameters [26]. However, none of the abovementioned methods can be well applied on mountainous areas covered with forests. For road damage detection, preearthquake road vector map can be overlaid on postearthquake imagery to discover the roads from the imagery as well as their damage $[27,28]$. Road center line extraction method can be used to get roads from postearthquake imagery without aid of road vector data [29]. However, few of them mentioned such case that road damage is occluded by trees and the relationship between road damage and the surrounding geological hazards, such as landslides.

To overcome the abovementioned problems, this paper locates the landslides triggered by the Jiuzhaigou earthquake and presents a knowledge-based method for postearthquake road detection and road capacity assessment with consideration of the impact of landslide using high-resolution remote sensing images.

\section{Study Area}

The study area is located in Jiuzhaigou County, north of Sichuan Province, China, covering the major earthquakestricken area of Jiuzhaigou nature reserve, a UNESCO World Natural Heritage site [30]. Jiuzhaigou County is located in the northeastern margin of Qinghai-Tibetan Plateau. The altitude difference is up to 2000 meters from west to east. The county land area is about 5290 square kilometers and its coordinates' range is $32^{\circ} 53^{\prime} N-33^{\circ} 43^{\prime} N, 103^{\circ} 27^{\prime} E-104^{\circ} 26^{\prime} E$. As shown in Figure 1, the study area (marked in red rectangle) is the place for experimental purposes.

A magnitude 7.0 earthquake struck Jiuzhaigou on 8 August 2017 at the depth of 20 kilometers [31]. The epicenter was located at $33^{\circ} 12^{\prime} \mathrm{N}, 103^{\circ} 49^{\prime} \mathrm{E}, 5$ kilometers west away from the $\mathrm{Y}$-shaped valley, the core area of Jiuzhaigou nature reserve. It is the third major tectonic earthquake having struck mountainous areas of Sichuan in the past decade after the Wenchuan earthquake in 2008 (about $200 \mathrm{~km}$ south of Jiuzhaigou) and the Lushan earthquake in 2013 (about $360 \mathrm{~km}$ south of Jiuzhaigou). 25 people died and more than 500 people were injured by this earthquake. Extensive damage was done to roads in Jiuzhaigou natural reserve as a result of landslides and falling rocks. From the comparison of remote sensing pre- and postearthquake images in Figures 2(a) and 2(b), it can be found that there are many landslides along the roads, and the roads on the images preearthquake were obvious and continuous; the roads were interrupted due to the influence of landslides after the earthquake. Figures 2(c) and 2(d) show the field survey figures of landslide and road damage in the study area.

\section{Data}

Since launched in 2015, BJ-2 satellite image has been widely used in many land monitoring applications in China as it provides the practical and successful combination of spatial resolution and time resolution. BJ-2 image is a constellation with three Earth observation satellites acquiring data in 4 bands (red, green, blue, and infrared). The red, green, and blue bands are imaged at $0.8 \mathrm{~m}$ resolution and the infrared band is imaged at $3.2 \mathrm{~m}$ resolution. The constellation can view the entire Earth's surface every day. The image catalog can be accessed from the gateway of BJ-2 satellite constellation service system. The images are pushed to the authorized users on demand via private service networks when the receiving server and the sending server are well connected. Once a disaster occurs, the three satellites' orbits can be adjusted by programming to capture the latest images of the specific regions. On 9 August 2017, the postearthquake images of Jiuzhaigou had been acquired. Meanwhile, the preearthquake BJ-2 satellite images with the least cloud influence acquired on 28 April 2017 were used to provide the land cover types before the earthquake event.

Road data covering the study area from China's first national geographic census results were used to provide the essential road information, such as accurate road centerlines, widths, and surface materials. The first national geographic census was initiated by the Chinese government and had been successfully completed in 2016. During the census process, high-resolution remote sensing images were used for automatic interpretation and manual editing. Then, the results were refined by field surveying before finally issued. The final results are accurate with wide coverage for physical geography features and human geography features. Therefore, the road data used here is more reliable and more efficient than that being extracted only by remote sensing images, which is very important for quick disaster response.

In addition, the digital elevation model (DEM) data of Jiuzhaigou County from the Sichuan Bureau of Surveying, Mapping, and Geoinformation (SCBSM) was used to provide the information of terrain. The DEM data produced by SCBSM covers most of Sichuan Province with a spatial resolution of 5 meters, which facilitates the landslide extraction with detailed slope information. The data sources are shown in Table 1.

\section{Methods}

This study estimates landslides triggered by the Jiuzhaigou earthquake and postearthquake road capacity. First of all, 

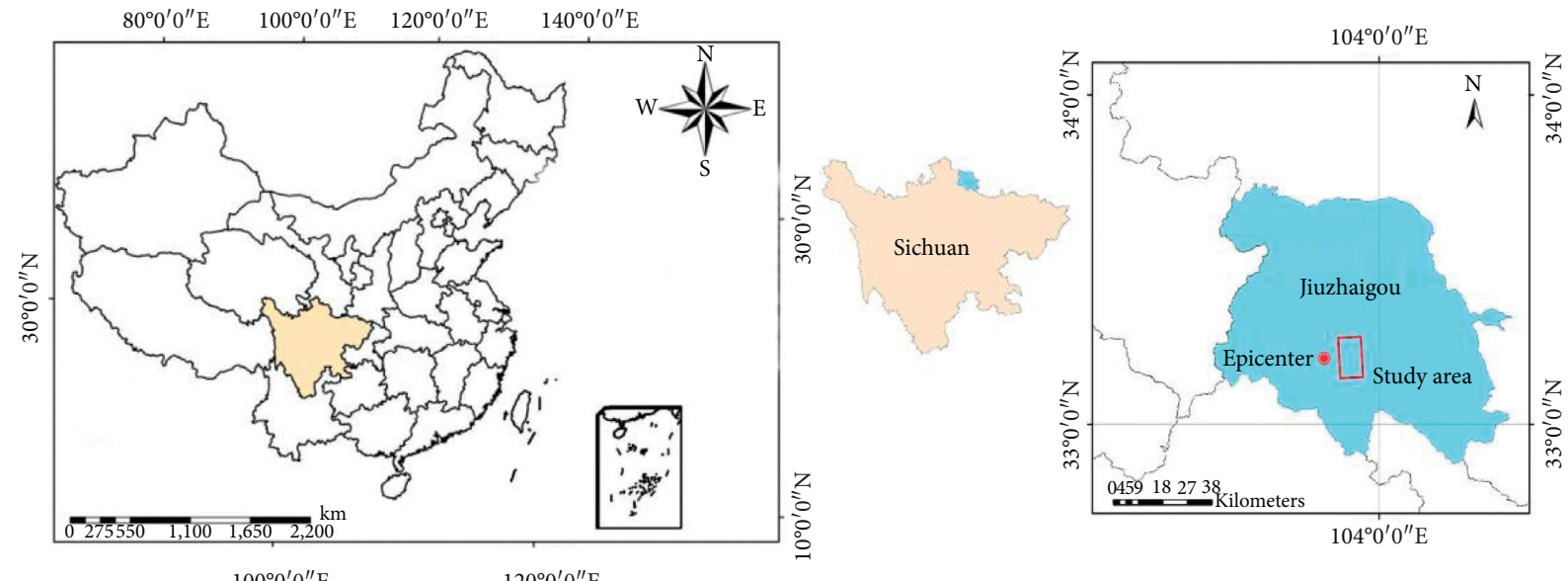

Figure 1: The location of the study area.

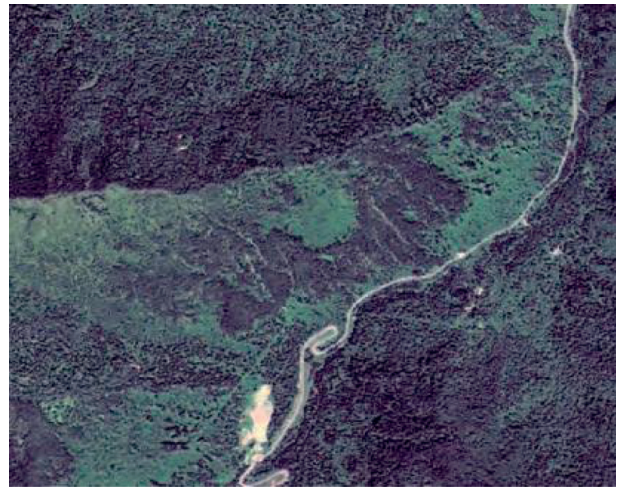

(a)

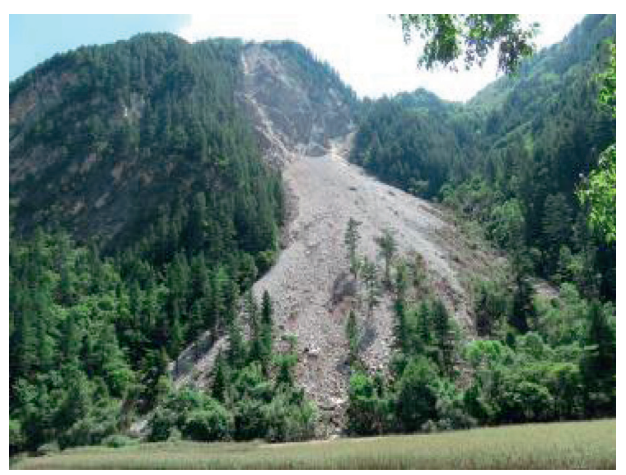

(c)

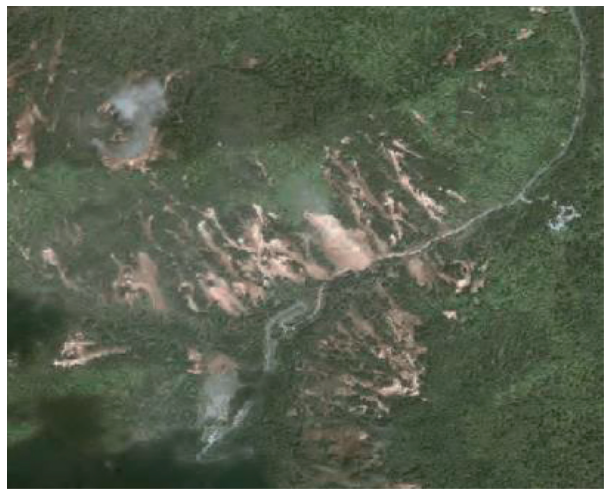

(b)

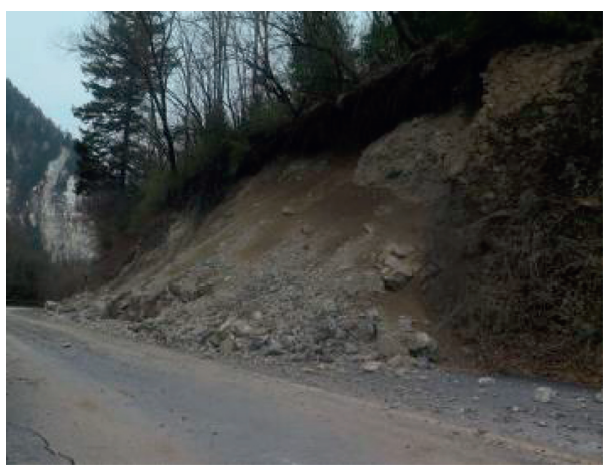

(d)

FIgURE 2: The situation before and after the earthquake in the study area. (a) The BJ-2 satellite image on April 28, 2017, before the earthquake. (b) The BJ-2 satellite image on August 9, 2017, after the earthquake. (c) Field survey figure of the landslide. (d) Field survey figure of road damage.

TABLE 1: Data sources.

\begin{tabular}{lcc}
\hline Data sources & Acquisition time & Spatial resolution \\
\hline BJ-2 images & $2017-04-28$ (before earthquake) & $0.8 \mathrm{~m}$ (panchromatic band) $/ 3.2 \mathrm{~m}$ (multispectral images) \\
Road data & $2017-08-09$ (after earthquake) & $0.8 \mathrm{~m}$ (panchromatic band)/3.2 m (multispectral images) \\
DEM & 2016 & - \\
\hline
\end{tabular}


with the support of ENVI 5.3 software, radiometric calibration, atmospheric correction, and geometric correction have been carried out. There are three crucial procedures in this study: landslide detection, postearthquake road detection, and road capacity assessment. Landslides are extracted from high-resolution remote sensing images firstly and are used to assist the detection of the postearthquake roads. The postearthquake roads are extracted based on preearthquake road data from China's first national geographic census results and postearthquake high-resolution remote sensing images using the knowledge-based model. Potential postearthquake roads are further deduced by performing spatial analysis of roads and their adjacent landslides. The road capacity assessment is conducted on the basis of the assessment model. The detailed procedures are illustrated in Figure 3.

\subsection{Landslide Extraction}

4.1.1. Land Cover Change Detection. The natural land cover of the study area was acquired by remote sensing image interpretation and field investigation, as shown in Table 2. In this mountainous area, the major natural coverage type is vegetation; other vegetated areas are dominated by the alpine and subalpine shrubs and meadows. In this region, the lands are prohibited to be exploited for commercial or agricultural purpose, where only some sparse settlements are located. When the earthquake erupted on 8 August 2017, these plants were almost at the peak of growth. Therefore, the land cover change caused by a landslide during the earthquake would result in an explicit distinction of vegetation in this area.

The Normalized Difference Vegetation Index (NDVI) and the Enhanced Vegetation Index (EVI) are two vegetation indices extensively used for vegetation canopy monitoring in remote sensing [32-34]. EVI was developed to improve NDVI production in some cases, which minimizes canopy-soil variations and improves sensitivity over dense vegetation conditions. But EVI is not suitable for medium and small regions. Therefore, NDVI is adopted in this paper to detect vegetation coverage change induced by landslides. The NDVI is calculated as

$$
\mathrm{NDVI}=\frac{\mathrm{NIR}-\mathrm{RED}}{\mathrm{NIR}+\mathrm{RED}}
$$

where NIR and RED are the infrared and red reflectance, respectively, from $\mathrm{BJ}-2$. The NDVI value ranges from minus one to plus one $([-1,1])$. Then, the rate of change (ROC) between NDVI before and after the earthquake was derived by

$$
\mathrm{ROC}_{\mathrm{NDVI}}=\frac{\mathrm{NDVI}_{\text {pre }}-\mathrm{NDVI}_{\text {post }}}{\mathrm{NDVI}_{\text {pre }}},
$$

where $\mathrm{NDVI}_{\text {pre }}$ and $\mathrm{NDVI}_{\text {post }}$ are the NDVI before and after the event, respectively. The smaller the absolute $\mathrm{ROC}_{\mathrm{NDVI}}$ $\left(\mid \mathrm{ROC}_{\mathrm{NDVI}} \mathrm{l}\right)$ is, the less the change of vegetation coverage occurred.
The variation of $\mathrm{ROC}_{\mathrm{NDVI}}$ during several months in the mountainous area may be caused by vegetation growth and agricultural or forestry activities. As shown in Table 1, there is less farmland in the study area and it is prohibited to cut woods in a natural reserve, which excludes the possibility of sharp $\mathrm{ROC}_{\mathrm{NDVI}}$ plunge induced by harvest and tree cutting. Moreover, when $\mathrm{ROC}_{\mathrm{NDVI}}$ is negative, it indicates that the plants have grown for seasonal change. Otherwise, when ROC $_{\text {NDVI }}$ is positive, the mean value of the regional ROC $_{\text {NDVI }}$ was calculated and analyzed. Then, a threshold was determined to discriminate the vegetation coverage change caused by landslides.

4.1.2. Landslides Identification. More criteria need to be integrated to eliminate the misclassified objects after ROC $_{\text {NDVI }}$ process. In the study area, with the consideration of image acquisition time span from late April to August, the positive $\mathrm{ROC}_{\mathrm{NDVI}}$ value may result from four situations, that is, (a) size increase of water body, (b) size reduction of rocky area, (c) variation of settlements, and (d) variation of landslide area. The water body and settlements are always distributed on the relatively plain places in the mountainous area with a gentle slope, while the regions of landslides are with a moderate or steep slope $[35,36]$. Therefore, the slope can be used to distinguish (b) and (d) from the other two situations of positive $\mathrm{ROC}_{\mathrm{NDVI}}$ variation. Research shows that the mean slope of water body (such as lake) above $1000 \mathrm{~m}$ is less than $5^{\circ}$ and that of the settlements is less than $12^{\circ}$ [37]. The threshold slope values were adopted and slightly adjusted experimentally. On the other hand, the starting region of landslide is as bright as bare rock but it is usually brighter than the following accumulation region of landslide which comprises more debris, woods, and dust. Therefore, the bare lands with brightness variation within an empirical limit range can be detected as a landslide area. Since the spatial resolution of RGB bands and infrared band of BJ-2 satellite image is $1 \mathrm{~m}$ and $4 \mathrm{~m}$, respectively, and that of DEM data is $5 \mathrm{~m}$, more landslide details can be noticed. Moreover, for the study area, of approximately $1000 \mathrm{~km}^{2}$, the landslides can be identified in about one hour using a computer with Core i7 CPU 3.4 GHz, RAM 16 GB.

\subsection{Road Damage Detection}

4.2.1. Postearthquake Road Extraction. Road centerline is crucial for road extraction and damage assessment. In the mountainous area where the land is covered with vegetation and terrain varies frequently, the road may be no longer with regular and continuous boundaries in remote sensing images. The road centerline may also be occluded by tree shade or upper rocks in preearthquake remote sensing images. For postearthquake images, the road centerline may be interrupted by shock and landslide for a certain length. Therefore, the existing methods for road centerline extraction are hard to be applied to practical operation in this study. As a result, the road data from China's national geographic census results are adopted. The data includes the existing surfaced roads with their centerlines and widths in this region which 


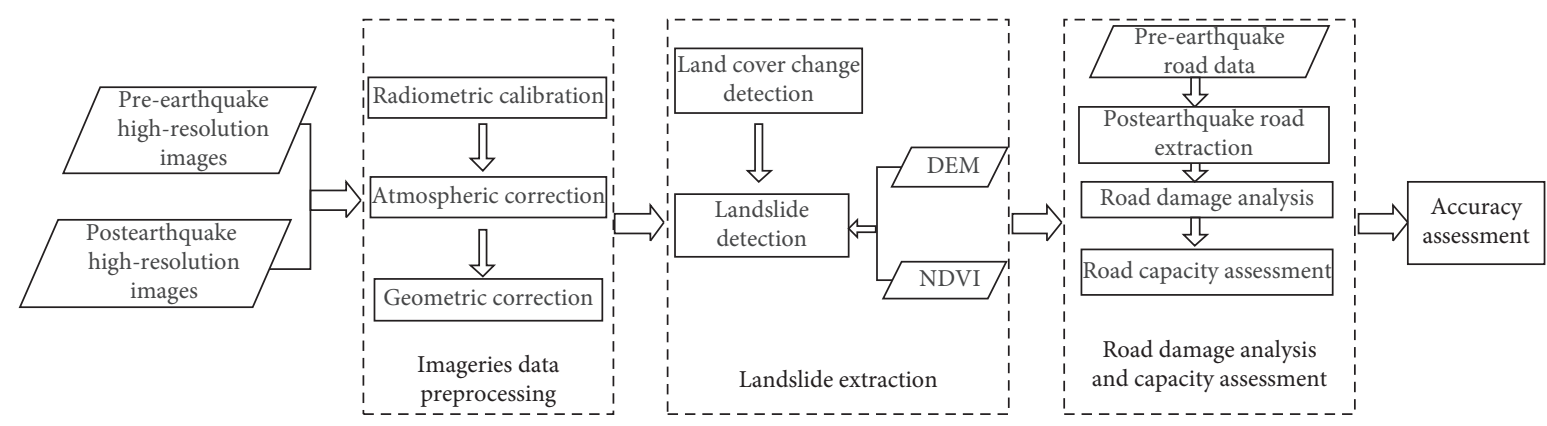

FigURE 3: Flowchart of quick estimation of landslides and postearthquake road capacity.

TABle 2: Main natural land cover of Jiuzhaigou.

\begin{tabular}{lc}
\hline Land cover type & $\begin{array}{c}\text { Area } \\
\text { percentage }\end{array}$ \\
\hline Alpine shrub & 2.24 \\
Sabina saltuaria forest & 0.12 \\
Alpine meadow & 0.78 \\
Deciduous broad-leaved forest & 4.44 \\
Abies ernestii forest & 12.90 \\
Salix shrub & 0.31 \\
Bare rock & 19.10 \\
Subalpine deciduous broad-leaved shrub & 22.10 \\
Water & 0.51 \\
Evergreen coniferous and broad-leaved mixed & 6.4 \\
forest & 31.1 \\
\hline
\end{tabular}

were updated in 2016 and had been refined by field surveying.

After the earthquake, the characteristics of roads varied in terms of geometry and composition when they were damaged. It is difficult to extract postearthquake roads exactly and efficiently from the whole size of the image. In this study, an integrated method was proposed to discern postearthquake roads, which refers to GIS analysis and knowledge-based road recognition. The method consists of four major steps. Firstly, a buffer was generated for each road centerline with a distance larger than width/2 to ensure the coverage of both road boundaries. Only the image part overlaid by the buffer areas was selected for following road detection. Then, typical parameters based on road knowledge and spectral characteristics were chosen to build the model for road extraction. Subsequently, potential road segments were extracted by this model after multiscale segmentation of the buffer-constrained area. Finally, these potential road segments were processed by a mathematical morphological operation to get the final results.

In the mountainous area, winding roads are common where the buffer zones may be overlapped with each other. To overcome this problem, the buffer boundaries are dissolved when they intersect, as shown in Figure 4.

The objects become more distinct within the buffer area where roads can be extracted more efficiently, as shown in Figure 5. While developing a model based on road knowledge for extraction, texture or geometry is required to eliminate other misclassified objects, such as bare land and parking lot adjacent to road. Therefore, the brightness,

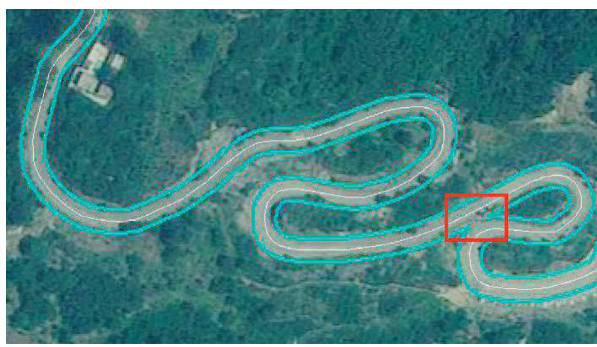

Figure 4: Winding road buffer with intact and dissolved boundaries.

standard deviation of RGB band, and rectangular fit are selected as quantitative parameters to further verify the postearthquake road segments. The expression of the model is as follows:

$$
\begin{aligned}
R_{1}=B \cap \mathrm{SD} \cap \mathrm{RF}, \quad & B \in\left(b_{1}, b_{2}\right), \mathrm{SD} \in\left(s d_{1}, s d_{2}\right), \\
& \mathrm{RF} \in\left(r f_{1}, r f_{2}\right),
\end{aligned}
$$

where $R_{1}$ is the postearthquake road segments and $B, \mathrm{SD}$, and RF are brightness, standard deviation, and rectangular fit of postearthquake road which should be within specific threshold ranges $\left(\mathrm{n}_{1}, n_{2}\right),\left(s d_{1}, s d_{2}\right)$, and $\left(r f_{1}, r f_{2}\right)$, respectively. These thresholds are predefined experimentally. Actually, trees along the road are still included in $R_{1}$. In order to remove them, $R_{1}$ is verified by using NDVI. The expression is as follows:

$$
R_{2}=R_{1} \cap \mathrm{NDVI}_{r d}, \quad \mathrm{NDVI}_{r d} \in\left(\mathrm{ndvi}_{1}, \mathrm{ndvi}_{2}\right),
$$

where $R_{2}$ denotes the final results of postearthquake road and $\mathrm{NDVI}_{\text {rd }}$ is NDVI value of road segment. The values of ndvi ${ }_{1}$ and $n d v i_{2}$ are predefined as a threshold for the NDVI value of the road segment.

The procedure using the foregoing model to extract postearthquake road segments is as follows:

(1) Multiscale segmentation is carried out by defining scale parameter, shape factor, and compactness. Pixels with a similar homogeneous pattern are grouped into the same image object. Spectral, shape, and level characteristics vary among different image objects.

(2) Each road vector data is buffered with a distance of larger than half-width. The road data and its buffer 


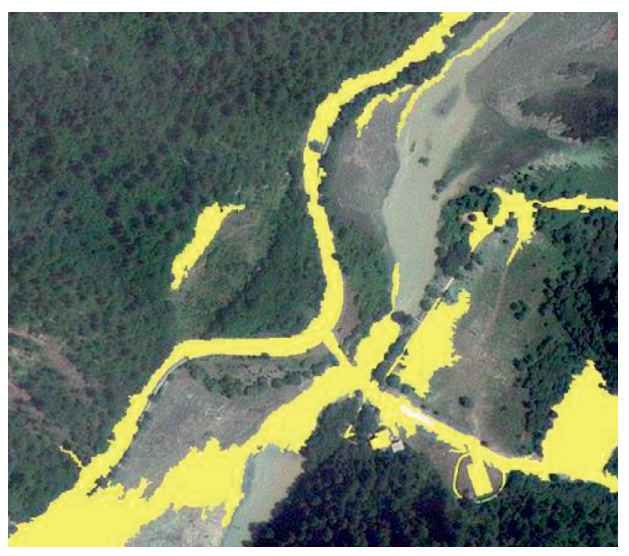

(a)

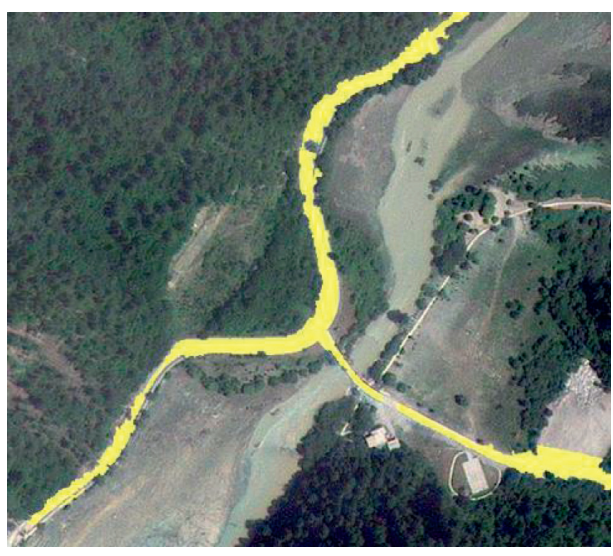

(b)

FIgURE 5: Classification results comparison. (a) Original classification result. (b) Buffer-constrained classification result.

area are overlapped on the postearthquake remote sensing image registered with the same spatial reference.

(3) Equation (3) is applied to the image part within the buffered area to extract road segments. Then, the results are further refined by equation (4).

(4) The extracted road segments of the same section with the consistent width are processed by the closing operation of mathematical morphology to remove the impact of small objects in image, such as vehicles. A $2 \times 2$ square is chosen as the structuring element so as not to affect the road segments.

4.2.2. Road Damage Analysis. In this paper, road damage analysis includes damage detection for observable roads in image and damage possibility inference for occluded roads. Firstly, the centerline buffered with the distance of width/ 2 is regarded as the preearthquake road. For observable road, the road surface is visible in image without occlusion, where the preearthquake roads consist of postearthquake undamaged roads and damaged roads. The relationship of them is defined as follows:

$$
\operatorname{Road}_{\text {damage }}=\text { Road }_{\text {pre }}-\text { Road }_{\text {post }} \text {, }
$$

where $\operatorname{Road}_{\text {pre }}$, Road ${ }_{\text {post}}$, and Road damage denote preearthquake road, postearthquake road, and damaged road, respectively. For occluded road, the road surface is partially visible in image, while the other parts are occluded by trees. In this case, the relationship is as follows:

$$
\operatorname{Road}_{\text {damage }}=\operatorname{Road}_{\text {pre }}-\operatorname{Road}_{\text {post }}+\Delta,
$$

where $\Delta$ denotes occluded roads in image. In this case, road centerline is buffered with a different distance specified as follows:

$$
D=0.5 \times \text { width }+60,
$$

where $D$ denotes the buffer distance and width denotes the width of road derived from the road vector data attribute.
Besides, a constant of 60 meters is determined to add to the buffer distance experimentally, which is used to infer the adjacent landslide impacts on roads.

In this study, it is agreed that road with landslide 60 meters or less away from its either boundary is prone to be damaged even if the damage is occluded by tree shade in image, because the occluded road may be damaged by secondary disasters induced by landslide from the upland, such as debris and fallen rocks. Otherwise, the occluded road is regarded as intact.

The spatial relationships between buffered area with distance calculated by equation (7) and landslides are intersection, touch, and none. By applying the INTERSECT operation, the common geometric portion of the buffer area and landslide is computed. If the common geometry is a polygon or point, it means that the occluded road is probably affected by the landslides and will be classified as a damaged road. $\delta$ in equation (6) is added to $\operatorname{Road}_{\mathrm{d}}$. If not, the occluded road is classified as preearthquake road and $\delta$ is appended to $\operatorname{Road}_{\mathrm{a}}$.

4.2.3. Road Capacity Grading Scheme Building. Road capacity grading plays an important role in postearthquake relief actions which can facilitate the rescue decision-making and help to provide timely assistance to victims. In many cases, it is reflected by road damage grades. Study of road damage reports due to earthquake from 1989 to 2012 gives five grades for damaged roads: extensively damaged roads (RDS-5), highly damaged roads (RDS-4), moderately damaged roads (RDS-3), low damaged roads (RDS-2), and slightly damaged roads (RDS-1) [38]. In China-related national standards, the road damage is graded by road section and five grades are defined as well based on the ratio of road structure damage.

In the study area, the road components vary with different road sections as the road direction and terrain change along the road. Furthermore, whether a postearthquake road section is passable for rescue vehicles is mainly determined by its width. In view of the above reasons, as well as relative study and the current national standards, this study proposes 
a postearthquake road capacity grading scheme based on postearthquake road width ratio $(\rho)$. The computation is as follows:

$$
\rho=\frac{W_{\text {post }}}{W_{\text {pre }}},
$$

where $W_{\text {post }}$ and $W_{\text {pre }}$ denote the post- and preearthquake road width, respectively. The grading scheme of postearthquake road capacity is built in Table 3 .

\section{Results and Discussion}

5.1. Landslide Extraction. In this paper, the landslides are extracted using pre- and postearthquake high-resolution remote sensing images and DEM data. As the study area in valley with lower elevation ranging from $2000 \mathrm{~m}$ to $3000 \mathrm{~m}$ compared with other nearby mountains, the snow disappeared in the preearthquake image which enables the use of NDVI to detect the land cover change. The whole process consists of land cover change rate detection based on NDVI and landslide extraction based on slope and brightness.

In order to detect the land cover change, the multiscale segmentation is used for image segmentation. The scale parameter is crucial because it determines the outlines of landslide objects as well as the boundaries of road objects. By analyzing the characteristics of images, the scale parameter is set to $50,100,150,200$, and 250. As the shapes of landslides vary and the widths of original roads range from $5.5 \mathrm{~m}$ to $7 \mathrm{~m}$, it is hard to define a scale value fitting for all these objects. After several trials and adjustments, the segmentation scale of 260 performs best on the landslide class and road class integrity.

After the calculation of NDVI for each object in different images, the results are exported to vector layers, respectively. Feature to raster was applied to these layers converting them to raster layers with the same cell size. The raster layers are then calculated to generate ROC map (Figure 6(a)). The steep decrease of NDVI change rate was found along the valley between the ranges of mountains. Using slope and brightness, the landslides are further extracted as shown in Figure 6(b). The result indicates that these landslides mainly distributed in the areas of valley banks which are also the areas with a steep slope. In these places, instable rocks are more vulnerable to ground shock.

5.2. Postearthquake Road Extraction. The postearthquake roads are extracted based on the buffer constrain and the knowledge-based model. Then, the results are improved by closing operation of mathematical morphology. Lastly, the road damage analysis model is applied to refine the results by inferring the potential undamaged parts. The final results are shown in Figure 7(a) where the visible segments of postearthquake road are identified and the occluded potential passible road segments are marked as well. In the above process, the buffer distance is set to one road width so as to guarantee the integrity of road boundaries.

The postearthquake image was acquired one day after the earthquake, so a few clouds' influence exists which is common for satellite images of the high-altitude region. However, the majority of this image can be seen clearly, especially for roads. On the bottom left of the image, the landslides are concentrated as shown in Figure 6(b) and roads in this region are severely destroyed. As a result, only a few scattered short road segments can be identified. On the middle top of the image, many interruptions along the road can be found, which is consistent with the fact that the landslides are dense in the nearby regions seen in Figure 6(b).

5.3. Road Capacity Evaluation. In order to evaluate the safety of roads for vehicles, the road capacity is calculated using equation (8) based on postearthquake roads' extraction result and preearthquake road vector data. Subsequently, the road capacity is graded based on the criteria scheme in Table 2. The result is shown in Figure 7(b) where green, orange, yellow, and red road segments map one-toone to four grades in Table 2.

It can be seen from Figure 7(b) that most road segments are accessible for vehicles. The orange road segments of grade II alternate with green road segments of grade I in the middle and upper image, which means that the rescue vehicles can pass through without any needs of road repair work despite some rocks or cracks may exist in the pavement, as shown in Figure 8(a). The red road segments of grade IV with a few yellow ones of grade III concentrate in the bottom-left image where Five Flower Lake lies. This is one of the hardest-hit areas in Jiuzhaigou natural reserve according to field investigation by the Institute of Crustal Dynamics, China Earthquake Administration [39-41]. The road pavements in this region are severely damaged as shown in Figure 8(b). It is impossible to rebuild the structure in short term to enable vehicles accessibility.

5.4. Accuracy Assessment. The landslides and road capacity in the study area are manually interpreted and delineated as well. The area of landslides and the length of postearthquake roads were computed to evaluate the accuracy of the foregoing automatic detection process. The results are listed in Table 4, where UA and PA denote user accuracy and producer accuracy, respectively.

It can be seen from the above table that the detection method is trustworthy. The PA can reach about $90 \%$ for landslide and $85 \%$ for postearthquake road. The detection result of landslide is more accurate than that of road because the landslides in image are comparatively distinct without shade occlusion. As most of the roads are located in valley with steep banks on both sides, the deduction method using landslide to estimate occluded road damage is feasible and effective. Otherwise, when the slope is gentle, the result may be different. Furthermore, the deviation inevitably exists in image registration process; as a result, the road centerlines cannot totally match with the postearthquake images. A few of them may drift slightly away from the places where they are supposed to be in images. In this case, although the number of drifted centerlines is small and the deviations are 
TABle 3: Postearthquake road capacity scheme.

\begin{tabular}{lccc}
\hline Grade & Road capacity & Road width ratio: $\rho$ & Criterion \\
\hline I & Almost normal road & $80 \%<\rho \leq 100 \%$ & The road surface is almost normal. Vehicles can pass through in succession. \\
II & Damaged but accessible road & $50 \% \leq \rho<80 \%$ & The road surface is partially damaged. Vehicles can pass through. \\
III & Damaged and interrupted road & $20 \% \leq \rho<50 \%$ & The road surface is severely damaged. Vehicles cannot pass through. \\
IV & Ruined road & $0 \leq \rho<20 \%$ & The road surface is ruined. \\
\hline
\end{tabular}

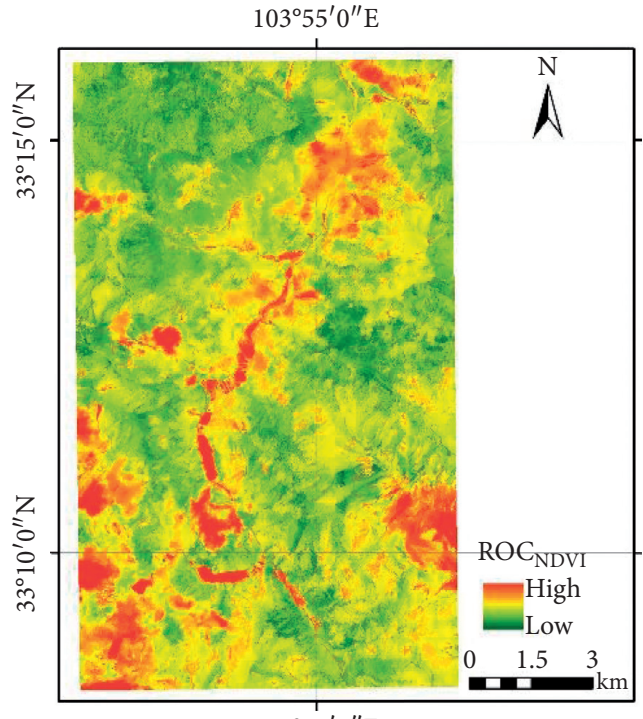

$103^{\circ} 55^{\prime} 0^{\prime \prime} \mathrm{E}$

(a)

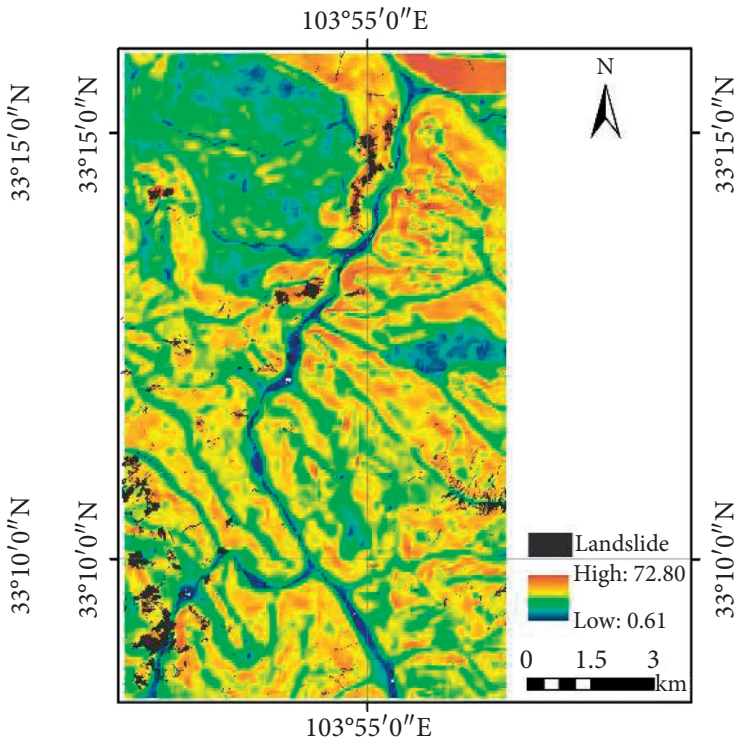

(b)

FiguRE 6: Results are exported to vector layers. (a) Rate of change (ROC) for NDVI between pre- and postearthquake images. (b) Detected landslides against slope in the study area.

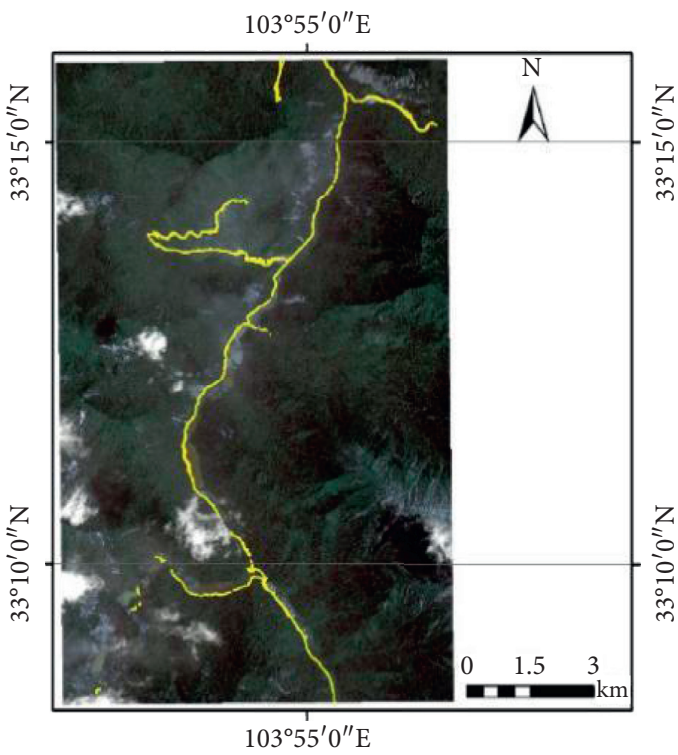

(a)

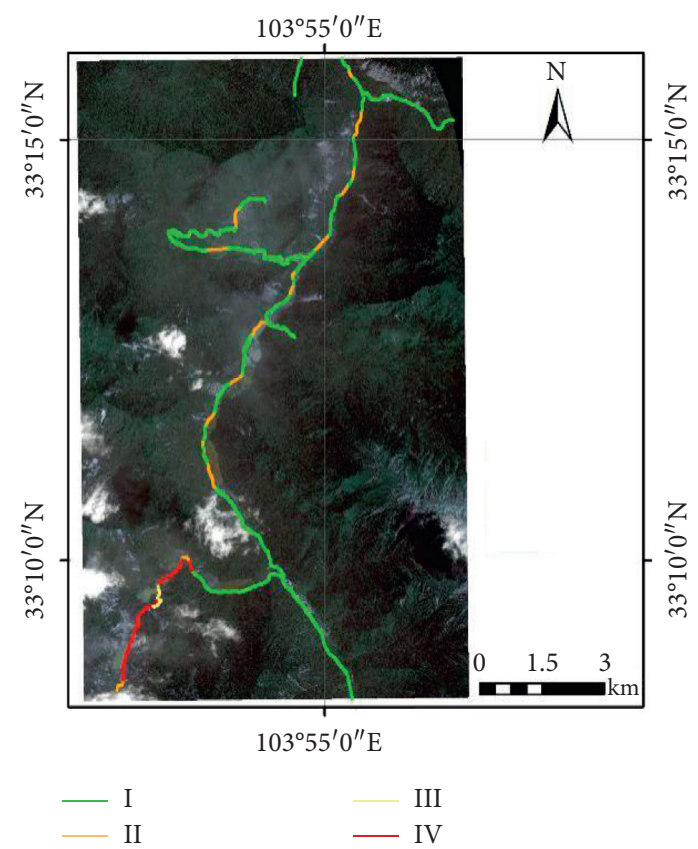

(b)

FIgURE 7: Extraction result. (a) Result of postearthquake road extraction. Yellow regions are the postearthquake roads. (b) Road capacity grade result. 


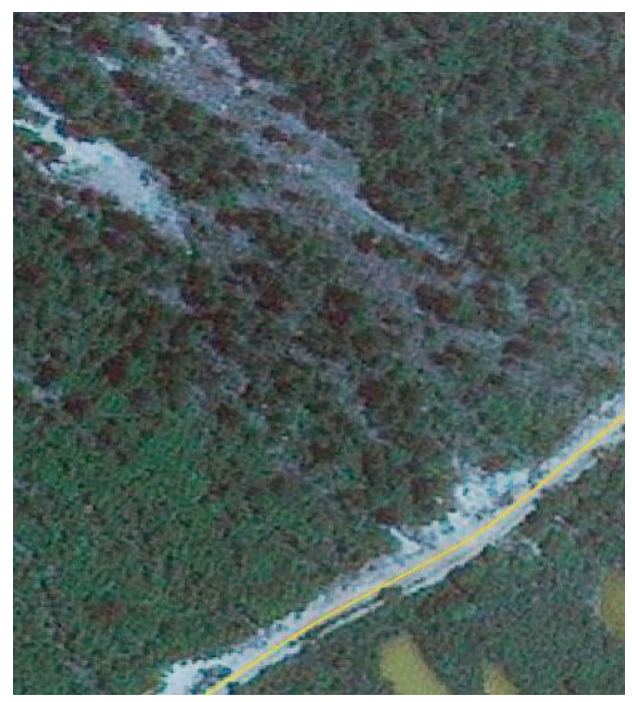

(a)

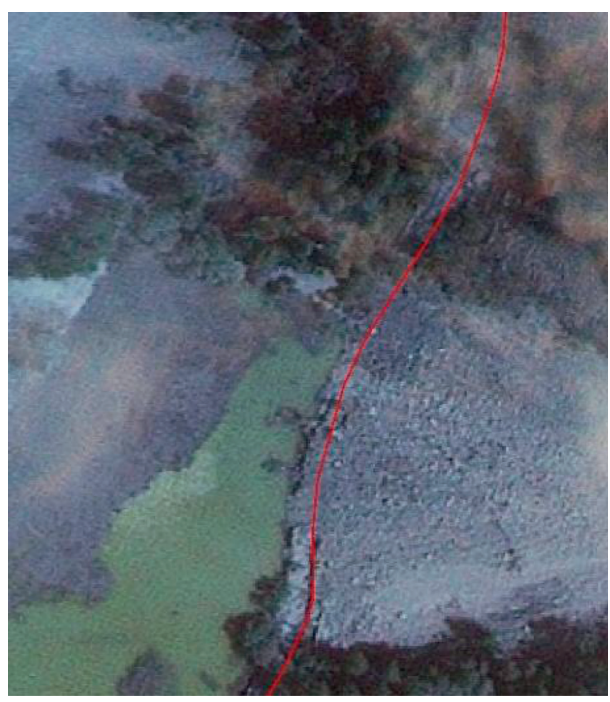

(b)

Figure 8: Road pavement damage cases. (a) Partially destroyed pavement with rocks caused by adjacent landslide. (b) Totally destroyed pavement buried by landslide.

TABle 4: Accuracy assessment of landslide and postearthquake road.

\begin{tabular}{lcccccc}
\hline Classification & Indicator & Manual interpreted value & Detected value & Correctly detected value & UA (\%) & PA (\%) \\
\hline Landslide & Area & $3.62 \mathrm{~km}^{2}$ & $3.84 \mathrm{~km}^{2}$ & $3.27 \mathrm{~km}^{2}$ & 85.16 & 90.33 \\
Postearthquake road & Length & $26.16 \mathrm{~km}$ & $27.84 \mathrm{~km}$ & $22.03 \mathrm{~km}$ & 79.13 & 84.21 \\
\hline
\end{tabular}

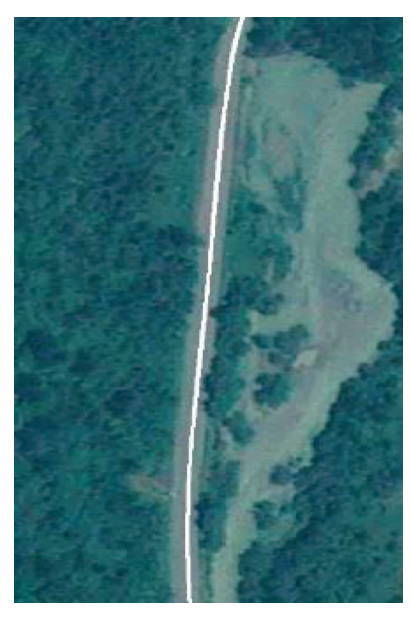

(a)

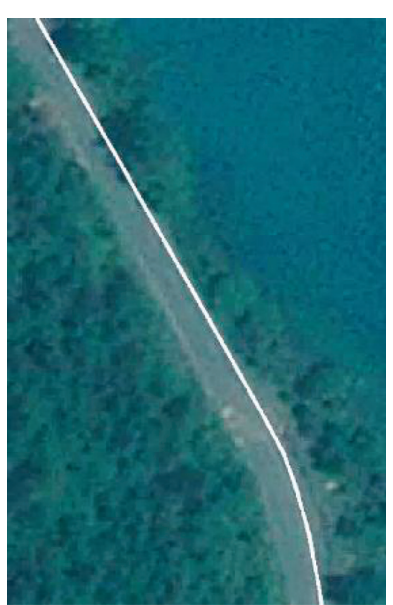

(b)

FIgURE 9: Road data deviation in the images. (a) Road data matches its position in image; (b) road data drifts from its position in image.

acceptable as shown in Figure 9, some errors may be generated.

The quantitative evaluation model of road capacity needs to introduce more quantitative values for analysis [42]. Limited by the research data, this paper lacks higher precision DEM data before and after earthquake to calculate the Earth volume accumulated on the road surface. Such three-dimensional information is needed to make a more accurate judgment on the road capacity. In addition, the quantitative assessment method of road capacity proposed in this paper is only aimed at the impact of the damaged object on the traffic condition of the road section. Other factors, such as road connectivity, topological structure, and road network relationship, are not taken into account. Therefore, the universality of the method should be strengthened in the follow-up study.

\section{Conclusions}

Landslides and postearthquake road capacity are the main factors after earthquake in the mountainous region that affect rescue work efficiency and quake-relief decision- 
making. It is extremely necessary to quantitatively estimate and map the landslides and postearthquake road capacity promptly and efficiently so as to carry out a quick response to the disaster and rescue more lives. To reduce the influence of cloud cover and meet the need for regional quick observation and feature extraction after the earthquake, this study proposes one landslide and postearthquake road detection method based on the vector data, high-resolution images, and DEM.

The main novelty of this approach is analyzing the connection between landslides and postearthquake road to estimate the occluded road damage. When earthquake occurs in mountainous area where cloud cover is common in remote sensing images, the existing data have to be fully utilized to generate fairly accurate interpretation results. NDVI variation and terrain slope are used to detect the landslides. Next, the observable postearthquake roads are extracted from the image. The occluded roads without landslide distributing in $60 \mathrm{~m}$ are also perceived as undamaged.

Experiments show good results for the proposed method to estimate the landslides and postearthquake road capacity. It is of great value for quick and efficient response to devastating earthquake in mountainous areas where the land is covered with vegetation.

\section{Data Availability}

The data supporting this research article are available from the corresponding author on request.

\section{Conflicts of Interest}

The authors declare that they have no conflicts of interest.

\section{Acknowledgments}

This research was supported by the National Key R\&D Program of China (2019YFC1510702), the National Natural Science Foundation of China (41701499), the Sichuan Science and Technology Program (2018GZ0265), and the Geomatics Technology and Application Key Laboratory of Qinghai Province (QHDX-2018-07).

\section{References}

[1] P. Cui, S. Liu, B. Tang et al., "Debris flow prevention pattern in national parks ??Taking the world natural heritage Jiuzhaigou as an example," Science in China Series E, vol. 46, no. 7, pp. 1-11, 2004.

[2] P. C. Yu, W. L. Zhou, and Y. B. Bai, "The dangerous assessment of geological hazards on the moving and settling construction land in nanan village of Sichuan Jiuzhaigou county," Research of Soil \& Water Conservation, vol. 13, no. 6, pp. 290-292, 2006, (In Chinese).

[3] Y. Du, F. Xie, Z. Wang et al., "Wenchuan earthquake surface fault rupture and disaster: a lesson on seismic hazard assessment and mitigation," International Journal of Geophysics, vol. 2012, Article ID 974763, 6 pages, 2012.

[4] C. Tang, J. Zhu, X. Qi, and J. Ding, "Landslides induced by the Wenchuan earthquake and the subsequent strong rainfall event: a case study in the Beichuan area of China," Engineering Geology, vol. 122, no. 1-2, pp. 22-33, 2011.

[5] T. Gorum, X. Fan, C. J. Van Westen et al., "Distribution pattern of earthquake-induced landslides triggered by the 12 May 2008 Wenchuan earthquake," Geomorphology, vol. 133, no. 3-4, pp. 152-167, 2011.

[6] X. L. Huang, H. L. Ran, W. T. Yang et al., "Evaluation of factors controlling large earthquake-induced landslides by the Wenchuan earthquake," Natural Hazards and Earth System Sciences, vol. 12, no. 12, pp. 3645-3657, 2012.

[7] S. Qi, Q. Xu, H. Lan, B. Zhang, and J. Liu, "Spatial distribution analysis of landslides triggered by 2008.5.12 Wenchuan earthquake, China," Engineering Geology, vol. 116, no. 1-2, pp. 95-108, 2010.

[8] L. Shen, C. Xu, L. Liu et al., "Interaction among controlling factors for landslides triggered by the 2008 Wenchuan, China Mw 7.9 earthquake," Frontiers of Earth Science, vol. 10, no. 2, pp. 264-273, 2016.

[9] C. Tang, G. Ma, M. Chang et al., "Landslides triggered by the 20 April 2013 lushan earthquake, sichuan province, China," Engineering Geology, vol. 187, pp. 45-55, 2015.

[10] R. Li, X. Wu, D. Yao, L. Peng, L. Ai, and J. Peng, "Susceptibility assessment of landslides triggered by the Lushan earthquake, April 20, 2013, China," IEEE Journal of Selected Topics in Applied Earth Observations and Remote Sensing, vol. 7, no. 9, pp. 3979-3992, 2014.

[11] S. Huang and Y. Peng, "Seismic stability analysis of saturated and unsaturated soil slopes using permanent displacement," Advances in Civil Engineering, vol. 2018, no. 1, 9 pages, Article ID 1786392, 2018.

[12] S. Huang, Y. Lyu, Y. Peng, and M. Huang, "Analysis of factors influencing rockfall runout distance and prediction model based on an improved KNN algorithm," IEEE Access, vol. 7, pp. 66739-66752, 2019.

[13] J. C. Borrero, "Field survey of northern sumatra and banda aceh, Indonesia after the tsunami and earthquake of $26 \mathrm{de}-$ cember 2004," Seismological Research Letters, vol. 76, no. 3, pp. 312-320, 2005.

[14] A. Suppasri, S. Koshimura, K. Imai et al., "Damage characteristic and field survey of the 2011 great east Japan tsunami in miyagi prefecture," Coastal Engineering Journal, vol. 54, no. 1, p. 1250005, 2012.

[15] F. Yamazaki and M. Matsuoka, "Remote sensing technologies in post-disaster damage assessment," Journal of Earthquake and Tsunami, vol. 01, no. 03, pp. 193-210, 2007.

[16] E. Booth, K. Saito, R. Spence, G. Madabhushi, and R. T. Eguchi, "Validating assessments of seismic damage made from remote sensing," Earthquake Spectra, vol. 27, no. 1, p. 157, 2011.

[17] K. S. Cheng, C. Wei, and S. C. Chang, "Locating landslides using multi-temporal satellite images," Advances in Space Research, vol. 33, no. 3, pp. 296-301, 2004.

[18] X. Yang and L. Chen, "Using multi-temporal remote sensor imagery to detect earthquake-triggered landslides," International Journal of Applied Earth Observation and Geoinformation, vol. 12, no. 6, pp. 487-495, 2010.

[19] J. Hervás, J. I. Barredo, P. L. Rosin, A. Pasuto, F. Mantovani, and S. Silvano, "Monitoring landslides from optical remotely sensed imagery: the case history of Tessina landslide, Italy," Geomorphology, vol. 54, no. 1-2, pp. 63-75, 2003.

[20] E. V. Marcelino, A. R. Formaggio, and E. E. Maeda, "Landslide inventory using image fusion techniques in Brazil," International Journal of Applied Earth Observation and Geoinformation, vol. 11, no. 3, pp. 181-191, 2009. 
[21] A. Pandey, P. P. Dabral, V. M. Chowdary, and N. K. Yadav, "Landslide hazard zonation using remote sensing and GIS: a case study of Dikrong river basin, Arunachal Pradesh, India," Environmental Geology, vol. 54, no. 7, pp. 1517-1529, 2008.

[22] P. D. Heermann and N. Khazenie, "Classification of multispectral remote sensing data using a back-propagation neural network," IEEE Transactions on Geoscience and Remote Sensing, vol. 30, no. 1, pp. 81-88, 1992.

[23] A. Kirthika and A. Mookambiga, "Automated road network extraction using artificial neural network," in Proceedings of the 2011 International Conference on Recent Trends in Information Technology (ICRTIT), Chennai, TN, India, June 2011.

[24] J. George, L. Mary, and K. S. Riyas, "Vehicle detection and classification from acoustic signal using ANN and KNN," in Proceedings of the 2013 International Conference on Control Communication and Computing (ICCC), Beijing, China, December 2013.

[25] C. Simler, "An improved road and building detector on VHR images," in Proceedings of the 2011 IEEE International Geoscience and Remote Sensing Symposium, pp. 507-510, Vancouver, BC, Canada, July 2011.

[26] C. Yang, R. Ramani Duraiswami, D. Dementhon, and L. Davis, "Mean-shift analysis using quasiNewton methods," in Proceedings of the 2003 International Conference on Image Processing, vol. 2, pp. 447-45003CH37429, Barcelona, Catalonia, Spain, January 2003.

[27] S. Davis, H. Ma, Y. Fan et al., "Road damage assessment from high resolution satellite remote sensing imagery in Wenchuan earthquake," Journal of Remote Sensing, vol. 12, no. 6, pp. 949-955, 2008, in Chinese.

[28] Q. M. Qin, H. J. Ma, J. Li et al., "Damage detection and assessment system of roads for decision support for disaster," Key Engineering Materials, vol. 467-469, pp. 1144-1149, 2011.

[29] J. Wang, Q. Qin, J. Zhao et al., "Knowledge-based detection and assessment of damaged roads using post-disaster highresolution remote sensing image," Remote Sensing, vol. 7, no. 4, pp. 4948-4967, 2015.

[30] J. L. Ye, S. L. Ustin, Y. Tang et al., "Basin-scale and travertine dam-scale controls on fluvial travertine, Jiuzhaigou, southwestern China," Geomorphology, vol. 180-181, pp. 267-280, 2013.

[31] G. Di, T. Lv, D. X. Sun et al., "SeismogeniC structure of the ms7.0 earthquake on August 8, 2017 in Jiuzhaigou, Sichuan," Journal of Geomechanics, vol. 23, no. 6, pp. 799-809, 2017.

[32] P.-Y. Chen, G. Fedosejevs, M. Tiscareño-LóPez, and J. G. Arnold, "Assessment of MODIS-EVI, MODIS-NDVI and VEGETATION-NDVI composite data using agricultural measurements: an example at corn fields in western Mexico," Environmental Monitoring and Assessment, vol. 119, no. 1-3, pp. 69-82, 2006.

[33] B. Matsushita, W. Yang, J. Chen, Y. Onda, and G. Qiu, "Sensitivity of the enhanced vegetation index (EVI) and normalized difference vegetation index (NDVI) to topographic effects: a case study in high-density cypress forest," Sensors, vol. 7, no. 11, pp. 2636-2651, 2007.

[34] E. Garroutte, A. Hansen, R. Lawrence et al., "Using NDVI and EVI to map spatiotemporal variation in the biomass and quality of forage for migratory elk in the Greater Yellowstone ecosystem," Remote Sensing, vol. 8, no. 5, p. 404, 2016.

[35] W. Zhang, J. Lin, J. Peng, and Q. Lu, "Estimating Wenchuan earthquake induced landslides based on remote sensing," International Journal of Remote Sensing, vol. 31, no. 13, pp. 3495-3508, 2010.
[36] A. Othman and R. Gloaguen, "Automatic extraction and size distribution of landslides in kurdistan region, NE Iraq," Remote Sensing, vol. 5, no. 5, pp. 2389-2410, 2013.

[37] T. R. Martha, N. Kerle, V. Jetten, C. J. van Westen, and K. V. Kumar, "Characterising spectral, spatial and morphometric properties of landslides for semi-automatic detection using object-oriented methods," Geomorphology, vol. 116, no. 1-2, pp. 24-36, 2010.

[38] P. Anbazhagan, S. Srinivas, D. Chandran et al., "Classification of road damage due to earthquakes," Natural Hazards, vol. 60, no. 2, pp. 425-460, 2012.

[39] C. Xu, S. Y. Wang, X. W. Xu et al., “A panorama of landslides triggered by the 8 August 2017 Jiuzhaigou, sichuan MS 7.0 earthquake," Seismology and Geology, vol. 40, no. 1, pp. 232-259, 2018, in Chinese.

[40] GB/T. 24336-2009, Classification of Earthquake Damage Tolifeline Engineering, China Earthquake Administration, Beijing, China, 2009, in Chinese.

[41] GB/T. 18208.4-2011, Post-earthquake Field Works-Part 4: Assessment of Direct Loss, China Earthquake Administration, Beijing, China, 2011, in Chinese.

[42] S. D. Jawak and A. J. Luis, "A comprehensive evaluation of PAN-sharpening algorithms coupled with resampling methods for image synthesis of very high resolution remotely sensed satellite data," Advances in Remote Sensing, vol. 02, no. 04, pp. 332-344, 2013. 